\title{
White-handed gibbons discriminate context-specific songs compositions
}

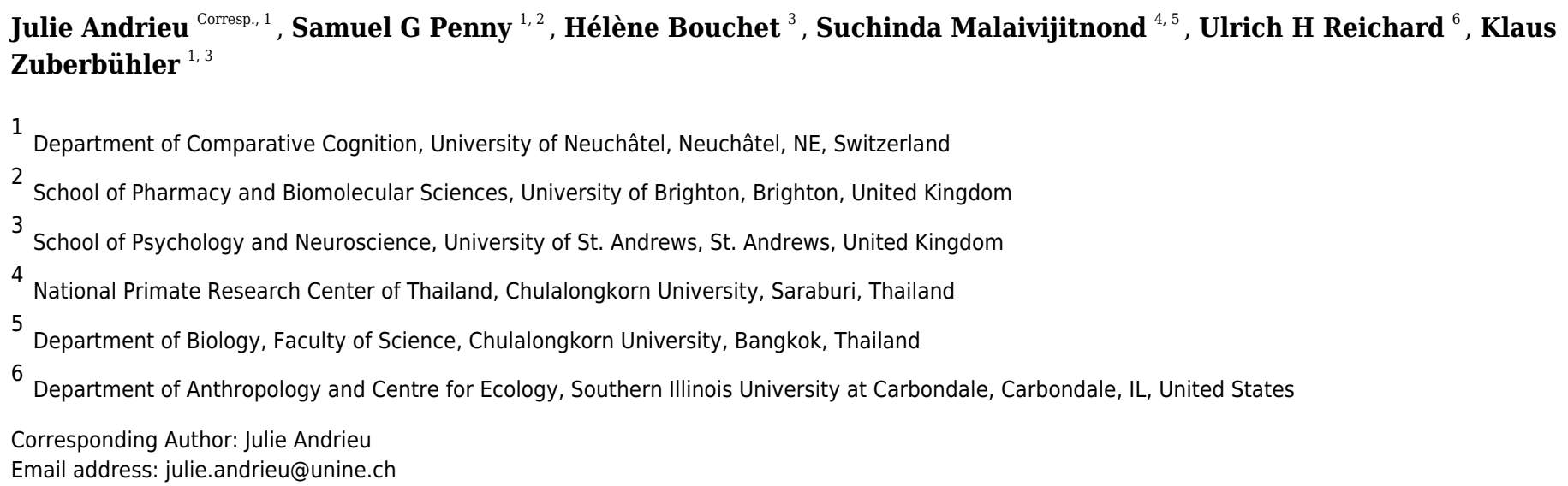

White-handed gibbons produce loud and acoustically complex songs when interacting with their neighbours or when encountering predators. In both contexts, songs are assembled from a small number of units although their composition differs in context-specific ways. Here, we investigated whether wild gibbons could infer the 'meaning' when hearing exemplars recorded in both contexts (i.e. 'duet songs' vs. 'predator songs').We carried out a playback experiment by which we simulated the presence of a neighbouring group producing either its duet or a predator song in order to compare subjects' vocal and locomotor responses. When hearing a recording of a duet song, subjects reliably responded with their own duet song, which sometimes elicited further duet songs in adjacent groups. When hearing a recording of a predator song, however, subjects typically remained silent, apart from one of six groups who replied with its own predator song. Moreover, in two of six trials, playbacks of predator songs elicited predator song replies in non-adjacent groups. Finally, all groups showed strong anti-predator behaviour to predator songs but never to duet songs. We concluded that white-handed gibbons discriminated between the two song types and were able to infer meaning from them. We discuss the implications of these findings in light of the current debate on the evolutionary origins of syntax. 
1 White-handed gibbons discriminate context-specific songs compositions

2

3

4

Julie Andrieu ${ }^{1}$, Samuel. G. Penny ${ }^{1,2}$, Helene Bouchet ${ }^{3}$, Suchinda Malaivijitnond ${ }^{4,5}$, Ulrich H. Reichard $^{6}$ \& Klaus Zuberbühler ${ }^{1,3}$

${ }^{1}$ Department of Comparative Cognition, University of Neuchâtel, Switzerland

${ }^{2}$ School of Pharmacy and Biomolecular Sciences, University of Brighton, UK

${ }^{3}$ School of Psychology and Neuroscience, University of St Andrews, UK

${ }^{4}$ National Primate Research Center of Thailand, Chulalongkorn University, Saraburi, Thailand

${ }^{5}$ Department of Biology, Faculty of Science, Chulalongkorn University, Bangkok, Thailand

${ }^{6}$ Department of Anthropology and Centre for Ecology, Southern Illinois University, Carbondale, IL, USA

Corresponding Author:

Julie Andrieu ${ }^{1}$

88 Impasse des Evangiles, La Palme, 11480, France

Email address: j.andrieu.julie@gmail.com

\section{Abstract}

White-handed gibbons produce loud and acoustically complex songs when interacting with their neighbours or when encountering predators. In both contexts, songs are assembled from a small number of units although their composition differs in context-specific ways. Here, we investigated whether wild gibbons could infer the 'meaning' when hearing exemplars recorded in both contexts (i.e. 'duet songs' vs. 'predator songs'). We carried out a playback experiment by which we simulated the presence of a neighbouring group producing either its duet or a predator song in order to compare subjects' vocal and locomotor responses. When hearing a recording of a duet song, subjects reliably responded with their own duet song, which sometimes elicited further duet songs in adjacent groups. When hearing a recording of a predator song, however, subjects typically remained silent, apart from one of six groups who replied with its own predator song. Moreover, in two of six trials, playbacks of predator songs elicited predator song replies in non-adjacent groups. Finally, all groups showed strong anti-predator behaviour to predator songs but never to duet songs. We concluded that white-handed gibbons discriminated between the two song types and were able to infer meaning from them. We discuss the implications of these findings in light of the current debate on the evolutionary origins of syntax. 
37 Keywords: duet song, predator song, playback experiment, syntax, white-handed gibbons 38

\section{Introduction}

40 Primate vocal communication is characterised by species-specific repertoires of acoustically 41 distinct vocalisations, some of which are given in response to specific events. The classic 42 example is the vervet monkey (Chlorocebus pygerythrus) alarm call system, with acoustically 43 distinct call types given to different predator types (Seyfarth, Cheney \& Marler, 1980a,b).

44 However, beyond the fact that primate calls can convey relatively distinct meanings, additional 45 complexities have recently come to light, with corresponding implications for evolutionary theories of communication.

47

48 First, it is often difficult to characterise a particular call type as an acoustically discrete structural 49 entity. Instead, following in-depth investigation seemingly 'discrete' calls often display considerable amounts of acoustic variation, which may be meaningful to recipients (Keenan, 51 Lemasson \& Zuberbühler, 2013). For example, the acoustic structure of chimpanzee (Pan 52 troglodytes) rough grunts varies depending on the perceived quality of the food resource 53 (Slocombe \& Zuberbühler, 2005), whereas barbary macaque (Macaca Sylvanus) barks differ in 54 call duration and mean frequency range according to specific external disturbances (Fischer, 55 Hammerschmidt \& Todt, 1995, 1998; Fischer \& Hammerschmidt, 2006).

57 Second, context can play an important role in how animals interpret each other's calls. Evidence 58 is in terms of how ongoing context modifies how animals react to a specific call type (Zuberbühler, 2000a,b; Arnold \& Zuberbühler, 2013; Seyfarth \& Cheney, 2018), a mechanism already described by Smith (1977). Empirically, the way intention and external factors affect how primates infer meaning from signals is relatively poorly explored (Grice, 1969; Carnap, 62 1988; Scott-Phillips, 2010).

64 Third, call sequences can serve as powerful semantic vehicles beyond the contribution of 65 individual calls (Zuberbühler, 2019a). For instance, the number of roaring units per sequence in 66 Guereza colobus monkey (Colobus guereza) alarm roars depends on the nature of the danger 
67 (Schel, Tranquilli \& Zuberbühler, 2009). Another example is Campbell's monkeys

68 (Cercopithecus campbelli) alarm calling, with variation in call rates (Lemasson et al., 2010), call 69 combinations (Ouattara et al., 2009) and call permutations (Ouattara, Lemasson \& Zuberbühler, 70 2009a,b) depending on external events. Similar phenomena have been observed in putty-nosed 71 monkeys (Cercopithecus nictitans martini) (Arnold \& Zuberbühler, 2006a,b). Although these

72 findings show remarkable similarities to some aspects of human syntax in terms of combinatorial 73 and permutational properties, the implications for evolutionary theories of language are far from 74 clear, suggesting that more empirical work is needed (Bolhuis et al., 2018; Townsend et al., 75 2018; Zuberbühler, 2019b).

76

77 A relevant primate example of complex combinatorial structure is gibbon song. In most species, 78 mated pairs produce morning duets that appear to serve territorial and mate defence functions 79 (Haimoff, 1984; Raemaekers \& Raemaekers, 1985a; Geissmann, 2002; Terleph, Malaivijitnond 80 \& Reichard, 2015, 2016; J Andrieu, 2012-2014, unpublished data a). Social learning seems to 81 play some role in the acquisition of song (Koda et al., 2013) and production is subject to social 82 influence (e.g., changes in mating partners usually result in audible differences in song 83 coordination) (Geissmann, 1999; Terleph, Malaivijitnond \& Reichard, 2017). Like most other 84 primate calls, gibbon song contains information about caller identity (Oyakawa, Koda \& 85 Sugiura, 2007; Terleph, Malaivijitnond \& Reichard, 2015; Clink et al., 2017) and the caller's 86 physical condition (Barelli et al., 2013; Terleph, Malaivijitnond \& Reichard, 2016). Gibbon 87 songs are audible over long distances, up to $1 \mathrm{~km}$, much beyond an average gibbon home range 88 (Mitani, 1985), suggesting that they have evolved to communicate to outgroup individuals 89 (Raemaekers \& Raemaekers, 1985a, 1985b; Mitani, 1985; Terleph, Malaivijitnond \& Reichard, $902015,2016)$.

91 Interestingly, in white-handed gibbons (Hylobates lar), there is also evidence for context-specific 92 song types: duet songs are produced by the mated pair as part of their daily routine while 93 predator songs are given when facing a predator, such as a clouded leopard or python (Clarke, 94 Reichard \& Zuberbühler, 2006; J Andrieu, 2012-2014, unpublished data b). Both song types are 95 identical in terms of their note repertoires, although there are consistent differences in the 96 prevalence of certain notes and in how notes are combined into songs (Clarke, Reichard \& 97 Zuberbühler, 2006, 2015; J Andrieu, 2012-2014, unpublished data b). Predator songs are sung 
98 for longer than duet songs and produced by most group members. They function to deter 99 predators, recruit group members, and alert relatives in adjacent territories (Zuberbühler, Jenny 100 \& Bshary, 1999; Clarke, Reichard \& Zuberbühler, 2006; Matsudaira et al., 2018). In contrast, 101 duet songs function in mate and territorial defence (Marshall \& Marshall, 1976; Raemaekers \& 102 Raemaekers, 1985a; J Andrieu, 2012-2014, unpublished data a). Duet songs may also function as 103 indicators of the strength of the social bond of the mated pair, a kind of relationship marker, 104 evidenced by the fact that newly formed pairs appear to go through a lengthy phase of adjusting 105 their relative vocal contributions towards a well-adjusted duet song (Haimoff, 1984; Geissmann 106 \& Orgeldinger, 2000).

107

Here, we investigated whether gibbons could discriminate the two functionally and structurally 109 distinct song types (i.e. duet song and predator song), by broadcasting natural singing events of a neighbouring group simulated from a concealed speaker. We predicted that if gibbons discriminated between predator and duet songs then they should respond with the matching song types and with behaviour adequate to the situation. Specifically, in response to predator songs we predicted increased vigilance, increased defecation rates and any other type of anti-predator behaviour already reported in the literature (Boissy, 1995; Clarke, Reichard \& Zuberbühler, 2012). In response to duet songs, we predicted no changes to antipredator behaviour but duet song responses (Raemaekers \& Raemaekers, 1985a, b).

\section{Materials \& Methods}

119 Study site and subjects

120 This study was conducted in the Mo Singto-Klong E-Tau area of Khao Yai National Park, 121 Thailand $\left(101^{\circ} 22^{\prime} \mathrm{E}, 1^{\circ} 26^{\prime} \mathrm{N}\right), 130 \mathrm{~km}$ North-East of Bangkok. Data were collected from 122 December 2012 to August 2014. Thirteen fully habituated groups of white-handed gibbons were monitored, each comprising of a primary male, his mated female with her offspring and (in 5 cases) a secondary male, totalling $\mathrm{N}=53$ individuals at the time of the study. Due to a number of constraints, it was only possible to conduct playback experiments with six of the 13 groups (Table 1).

127 
130 Terminology

131 Following Raemaekers et al.'s (1984a) terminology we distinguished three sequence types within 132 each song: the introductory sequence (series of soft 'hoo' notes, followed by combinations of 133 other note types, such as 'oo', 'wa', 'leaning wa' and 'wa-oo'); the great call sequence 134 (idiosyncratic female call sequence, usually followed by her male's 'coda' response). In duet 135 songs, the first great call sequence usually appears within the first two minutes. Great call 136 sequences can be repeated multiple times (about once every 1-2 min) (Raemaekers, Raemaekers 137 \& Haimoff, 1984a; Clarke, Reichard \& Zuberbühler, 2006; Terleph, Malaivijitnond \& Reichard, 138 2016), in which case they are separated by an interlude sequence (any notes given after a great call sequence, including the final one) (Ellefson, 1968; Raemaekers et al., 1984a) (Fig 1 \& 2-a).

140

141

142

143

144

145

146

147

148

149

150

151

152

153

154

155

156

157

158

159

The same three sequence types can also be found in predator songs although, overall, they differ in length and are produced with the contribution of most group members. When comparing predator songs with duet songs, for the introductory sequence the initial 'hoo' notes series are longer and contain more 'hoo' notes, followed by fewer 'leaning wa' notes and more 'hoo' notes (Clarke, Reichard \& Zuberbühler, 2006). The great call sequence is also different, mainly because males respond more rapidly with their answering coda (Clarke, Reichard \& Zuberbühler, 2006). Regarding the interlude sequence, predator songs contain more 'sharp wow' notes, especially towards the end of the song, compared with duet songs (Clarke, Reichard \& Zuberbühler, 2006) (Fig 1 \& 2-b).

\section{Figure 1.}

\section{Figure 2.}

$\underline{\text { Stimulus collection }}$

Duet songs were recorded on an all-occurrence basis during all-day follows of study groups (Table 1) until at least one song suitable as playback stimulus was recorded, i.e., a high-quality song with minimum background noise, singing individuals at a maximum distance of 30 metres from the recording device. Predator songs were induced by presenting a realistic, life-size 
160 clouded leopard (Neofelis nebulosa) model to each group following an established protocol (Fig. 161 3, Clarke, Reichard \& Zuberbühler, 2006; J Andrieu, 2012-2014, unpublished data b). Once a 162 group was located and before positioning the model, we ensured that on the same day the group 163 had (a) already produced at least one duet song more than one hour earlier (to verify a basic 164 motivation to sing), (b) not yet produced a predator song (nor its direct neighbours), (c) not had a 165 natural predator encounter since the beginning of the day-follow, nor heard other species' alarm

166 167 168 169 170 171

172 173 174

175 176

\section{7}

178

179 180

181

182 183 184 185 186 187 188 189 190 calls within the last hour, and (d) not had an intergroup encounter with a neighbouring group. If these conditions were met, we positioned the predator model on the group's anticipated travel direction outside their visual range. We then continuously recorded their vocal behaviour and scored the presence of any non-vocal anti-predator behaviour on an all-occurrence basis (branch dropping, defecation, vigilance). Duet and predator songs were recorded using directional microphones (Sennheiser MKH 815T \& Sennheiser ME66) with windshields connected to a digital stereo recorder (Marantz PMD660; settings $44.1 \mathrm{kHz}, 16$ bits) from December 2012 to August 2014.

\section{Figure 3.}

\section{$\underline{\text { Experimental protocol }}$}

Each group was tested once with each stimulus type, which resulted in a total of 12 trials $(\mathrm{N}=6$ duet songs; $\mathrm{N}=6$ predator songs, Table $\mathrm{S} 1$; minimum interval between trials: 1 week), all broadcasted before 12:00 local time (to match timing of natural duet song production). Prior to playback experiments, we measured the peak intensity of female great call climaxes in spontaneous duet songs (i.e., loudest notes, Terleph, Malaivijitnond \& Reichard, 2016) at an estimated recording distance of 10-20 m using a REED ST-805 [REEDinstruments, Wilmington, $\mathrm{NC}$ ] sound pressure metre (frequency range $31.5 \mathrm{~Hz}-8 \mathrm{kHz}$, measuring level range 30-130 dB, $0.1 \mathrm{~dB}$ resolution, accuracy $\pm 1.5 \mathrm{~dB}$ ). We measured three great call climaxes per female from the six song-providing groups (Table 1), which resulted in a mean sound pressure level of $78.2 \pm$ $8.0 \mathrm{~dB}(\mathrm{n}=18$; dB SPL, A-weighting sound pressure levels for general sound level measurements, and $125 \mathrm{~ms}$ fast time weighting). We then broadcasted songs such that subjects always heard recordings from one of their direct neighbours (Table S2), with comparable natural audibility (tested at each playback location with a decibel meter, matching climaxes SPL 
191 measurements, with real time adjustments in coordination with both experimenters depending on 192 weather conditions on the testing day) and from spatially realistic locations $15-20 \mathrm{~m}$ within the 193 canopy from where the song providing group had been seen before within the respective 194 territories.

195

196 We standardised the distance between the speaker and subjects to about 150m (mean \pm SD: 149 $197 \mathrm{~m} \pm 17 \mathrm{~m}$ ), with playback conditions randomly counterbalanced (Table S2). Stimuli were 198 broadcasted when the same conditions as for predator model presentation had been met, using a 199 Climate CL60-T2 speaker connected to a Kenwood KAC-5203 amplifier, in conjunction with a 200 Roland R-05 digital player.

201

202 Playback trials were carried out from spatially realistic locations, i.e., from the home range of the 203 song-providing group towards the home range of the target group. In doing so, we took a number 204 of precautions such that the song-providing group could not overhear its own song. Before each 205 trial, we ensured that the song-providing group was not in the vicinity of the speaker $(>100 \mathrm{~m}$ 206 radius). We then monitored the area for a period of 1 hour to further ensure that the song207 providing group was not nearby. For each trial, the speaker was positioned in the overlapping 208 zone between the song-providing and target group, such that it was facing away from the home 209 range centre of the song-providing group towards the target group.

210

\section{Data collection}

212 Due to the difficult visual conditions in the forest, it was impossible to continuously video-tape 213 the entire duration of trials nor to film all group members simultaneously. We therefore decided 214 to restrict observations to the primary male of each group. Males are easily identifiable by their 215 body hair colouration, facial features and genitals. Primary males were video recorded as long as 216 possible (i.e., until they moved out of sight) using a Panasonic SDR-S26 Camcorder. Videos 217 were coded using ELAN software [ELAN (V5.2) Nijmegen: Max Planck Institute for 218 Psycholinguistics]. Because the speaker location was visible on the video clips (outside camera 219 range) it was necessary for the experimenter to comment on the male's gazing direction during 220 filming, which made blind coding redundant. All video recordings are available on figshare 221 (https://doi.org/10.6084/m9.figshare.12363050.v1). 
222

223 Regarding long-term effects, we collected 5-min scan samples of the primary males' behavioural

224 activities, gaze directions, body positions, elevations $(\mathrm{m})$ and proximities to their female partners

225 (m) during 1 hour after each trial (i.e., 13 scans per trial; Table 2). Furthermore, we scored all

226 defecation/urination and branch dropping events over a two-hour period using all occurrence

227 sampling.

228

229 Table 2.

230

231

$\underline{\text { Vocal responses }}$

232 We digitised, analysed and compared songs given in response to both playback conditions, using

233 Raven Pro 641.4 [Cornell laboratory of Ornithology, Ithaca, NY]. For the introductory

234 sequence, we determined the duration of the initial 'hoo' notes series (s) and the corresponding

235 number of 'hoo' notes, the type of the first ten notes following the 'hoo' series, and the duration

236 of the introductory sequence (i.e., latency to the first female great call). We measured the interval

237 between the female great call and the male coda reply (s), the total song duration (s), and

238 determined whether a neighbouring group also produced a song and its type. Finally, we

239 identified the presence of 'sharp wow' notes and we measured the latency to the first 'sharp

240 wow' note (i.e. time elapsed in seconds between the onset of the song bout and the first 'sharp

241 wow' emitted).

242

243 This study was approved by the School of Psychology Ethics Committee of St. Andrews

244 University. Approval was given on the understanding that the ASAB guidelines for the

245 Treatment of Animals in Behavioural research and Teaching are adhered to $\left(\mathrm{n}^{\circ} 16112011\right)$. The

246 research permit was delivered by the National Research Council of Thailand (NRCT,

$\left.247 \mathrm{n}^{\circ} 0002 / 5841\right)$.

248

249 Data analysis

250 Behavioural responses

251 We compared behavioural responses within subjects and across playback conditions; the primary

252 males' latency and duration of first looks towards the speaker, the occurrence of 
253 defecations/urinations and branch droppings, the average distance to their female mates and the

254 heights (medians across all scan samples; Table 2). For categorical data (i.e., activity, body

255 position and gaze), we summed up and calculated for each individual the proportion of each

256 behaviour within the categories (see Table 2) and compared the behavioural pattern across

257 playback conditions.

258

259 Vocal responses

260 We compared the number of introductory 'hoo' notes and the duration of the introductory 'hoo' 261 notes series, the number of other relevant 'hoo' and 'leaning wa' notes within the first ten notes 262 following the introductory 'hoo' series, and the introductory sequence duration, within groups 263 and across conditions. For the great call sequence, we compared male response delays to the 264 female great calls. Finally, we compared the total song duration between playback conditions, 265 identified the presence of 'sharp wow' notes, and measured the latency to first 'sharp wow' note 266 produced.

267

268 Statistical procedures

269 Due to small sample sizes we opted for non-parametric statistics. Wilcoxon matched-pair signed270 rank tests were performed for behavioural data analysis, with exact significance levels reported 271 (Siegel \& Castellan, 1988; Mundry \& Fischer, 1998). For vocal data, we used Kruskal-Wallis 272 rank sum tests with a Benjamini \& Hochberg procedure to correct for multiple testing 273 (Benjamini \& Hochberg, 1995). Post-hoc tests were either Wilcoxon rank sum tests with 274 Benjamini \& Hochberg p-value adjustments or Dunn (1964)'s tests with Benjamini \& Hochberg 275 p-value adjustments for eventual ties. To compare the type of the first ten notes produced across 276 contexts we used a Pearson's Chi-squared test followed by Chi-squared post-hoc tests with 277 Benjamini \& Hochberg p-value adjustments. Statistical analyses were performed using R V3.5.1 278 (R core Team, 2018) with the significance level set at 0.05.

279

280 Results

281 Vocal behaviour

282 Response rates 
283 In the duet song condition, 5 of 6 groups responded with duet counter-singing to playbacks of 284 duet songs (Table S3). In addition, eight neighbouring groups that shared their borders with the 285 song-providing group or the tested group also produced duet songs during 3 of 6 trials $(\mathrm{N}=3$, $286 \mathrm{~N}=1, \mathrm{~N}=4$ neighbouring groups, respectively, see table $\mathrm{S} 4$ ), while none of them produced a 287 predator song.

288

289 In the predator song condition, 1 of 6 groups responded with a predator song to playbacks of a 290 predator song (within the first $10 \mathrm{~min}$, see Table S3). The response song contained a highly 291 delayed first great call and many 'sharp wow' notes, highly typical for a predator song. In 292 addition, two distant (non-neighbouring) groups also produced predator songs during 2 of 6 293 trials, again characterised by a delayed first great call and 'sharp wow' notes (Table S4). None of 294 the groups ever produced a duet song.

295

296 Song structure

297 Playbacks of duet songs reliably triggered synchronized singing by the mated pair of the target 298 groups. To confirm that these vocal responses $(\mathrm{N}=5)$ qualified as regular duet songs, we 299 compared them to both spontaneously produced duet songs and experimentally induced predator 300 songs (using a leopard model; Table 3 ) by the same groups.

301

302

Table 3.

303

304

First, there were significant differences across all six variables tested (Table 3), while subsequent 305 pairwise comparisons revealed significant differences between predator songs and the two other 306 song types, but not between spontaneous duet songs and response songs elicited by playbacks 307 (Table S5 for detailed pairwise comparisons).

308 Second, male latencies to reply to their females' great calls also differed significantly between 309 song types $\left(\chi^{2}(2)=33.90, P<0.001, \mathrm{~N}=82\right.$, Kruskal-Wallis rank sum test). Here as well, post-hoc 310 analyses revealed that males gave earlier replies to female great calls in the predatory context 311 (mean delay: $-1.7 \pm 1.6 \mathrm{~s}, \mathrm{n}=20)$ than in spontaneous duets $(0.6 \pm 0.7 \mathrm{~s}, \mathrm{n}=28)$ or playback duet 312 responses $(0.5 \pm 0.6 \mathrm{~s}, \mathrm{n}=34)(P<0.001$ in both cases $)$, with no difference between spontaneous 
313 and playback duet responses $(P=0.530$; Dunn's post-hoc test for multiple comparisons, with 314 Benjamini \& Hochberg correction).

315 Finally, we compared the first ten notes produced by males and females immediately following 316 the introductory 'hoo' note series (mean duration: $10.50 \pm 2.8 \mathrm{~s}, \mathrm{n}=30$, accounting for a total of 317100 notes per song type). Significant differences were found between song types regarding their 318 early note composition in 'hoo' and 'leaning wa', but also in 'wa-oo' notes $\left(\chi^{2}(4)=96.86, P<\right.$ 319 0.001, Pearson's Chi-squared test). Predator songs contained more 'hoo' notes and fewer 320 'leaning wa' notes than duet songs, with no differences between spontaneous and playback duet 321 responses. However, 'waao' notes were more common in playback duet responses than

322 323 324

325

326

327

328

329

330

331

332

333

334

335

336

337

338

339

340

341

342 343 spontaneous duet songs, and again in spontaneous duet songs than predator songs (Table S6 for detailed pairwise comparisons).

\section{$\underline{\text { Non-vocal behaviour }}$}

We were able to record the immediate behavioural responses of primary males in 5 of 6 groups (Table 1). All males responded by turning their heads towards the speaker, albeit with no latency differences across playback conditions (median duet: $1.1 \pm 1.8 \mathrm{~s}$, predator $2.8 \pm 3.3 \mathrm{~s}, V=2, P=$ $0.188, \mathrm{~N}_{\text {duet }}=5, \mathrm{~N}_{\text {Predator }}=5$, Wilcoxon matched-pair signed-rank test, Fig 4a). Additionally, we found a trend (although not significant) towards longer gaze duration in the predator than the duet song condition (median duet: $2.0 \pm 1.4 \mathrm{~s}$, predator: $12.6 \pm 6.1 \mathrm{~s}, V=0, P=0.063, \mathrm{~N}_{\text {duet }}=5$, $\mathrm{N}_{\text {Predator }}=5$, Wilcoxon matched-pair signed-rank test, Fig 4b).

\section{Figure 4 .}

For long-term behavioural responses, we collected data on all 6 primary males and found no differences across playback conditions in grooming, resting and displacement activities but a significant difference in feeding, with individuals less likely to engage in feeding activities after predator than duet song playbacks (Table 4). Regarding anti-predator behaviours, we found no differences in canopy use, distance between mates, and number of branch droppings across conditions. However, males were more vigilant and defecated significantly more often following predator compared with duet song playbacks (Table 4). 


\section{Table 4.}

345

346 Following playback of a predator song, males increased their vigilance activity (Fig 5), directed

347 more gazes towards the ground (Fig 6a) and less towards the upper canopy (Fig 6b) compared

348 with duet treatment (Table 4).

349

350

\section{Figure 5.}

351

352

Figure 6.

353

\section{Discussion}

355 Summary

356

357

358

359

360

361

362

363

364

365

366

367

368

369

370

371

372

373

374

White-handed gibbons produce two structurally distinct songs in context-specific ways; duet songs (in non-predatory contexts) and predator songs (to clouded leopards and other predators). The two song types differ in the overall duration, frequency and distribution of specific notes ('hoo', 'leaning wa', 'sharp wow') and in the location of the female great calls and male replies within each song. In this study, we investigated whether individuals discriminated between these two structurally different song types and whether they could infer meaning from them. We found several lines of evidence in favour of such an ability. First, playbacks of duet songs reliably elicited natural duet song replies (identifiable by several acoustic parameters) in neighbouring groups and in more distant groups, similar to how natural duet song spread throughout the forest (Raemaekers \& Raemaekers, 1985b; J Andrieu, 2012-2014, unpublished data a). Second, playbacks of predator songs never triggered duet songs in any group, but occasionally predator song replies (identifiable by several acoustic parameters) in one of six neighbouring groups and two non-neighbouring distant groups. Finally, subjects consistently showed anti-predator behaviours (vigilance, ground scanning, defecation) and a tendency for longer first look towards the speaker after predator compared to duet song playbacks. Based on these data, we concluded that white-handed gibbon song conveys key information about the world, which is made accessible to recipients by a number of structural regularities. This conclusion fits with previous research by Clarke et al. (2006) who first demonstrated the presence of structural differences in white-handed gibbon songs. 
376 Singing as anti-predator behaviour

377 Similar to other large cats, clouded leopards are opportunistic predators that attack both

378 terrestrial and arboreal species, including primates (Rabinowitz, Andau \& Chai, 1987; Grassman, 379 2001). Hence, a somewhat surprising finding was that subjects remained mostly silent to others' 380 predator songs, despite showing strong anti-predator behaviour (males and females appeared to 381 behave in the same way, i.e., ground scanning, vigilance, defecation). The lack of vocal response 382 may be part of a cryptic strategy to conceal the group's location when a dangerous stalking 383 predator is presumed in the vicinity (Aguilar de Soto et al., 2012; Grow, 2019). However, this 384 does not explain why 1 of 6 target groups and two distant groups still responded with predator 385 songs to the playbacks. It is possible that gibbons pursue a flexible vocal strategy, altering 386 between 'crypsis' and 'perception advertisement' depending on perceived personal risk, the 387 ability to benefit neighbouring relatives, and the likely dissuasive effect on the predator itself 388 (Zuberbühler, Jenny \& Bshary, 1999; Clarke, Reichard \& Zuberbühler, 2006).

389 Equally relevant is the fact that the three predator song responses were shorter than natural 390 predator songs (Tables S3 and S4). We can think of several explanations for this finding. First, as 391 mentioned already, it is possible that groups tried to minimise their own exposure to the predator 392 if they decided to respond to another group's predator song. Second, differences in predator song 393 duration may function as indicators for perceived urgency, with longer songs indicating more 394 serious threats than shorter songs. We find this less likely to be an evolved function since 395 listeners would have to wait for (and compare) considerable amounts of time periods before 396 extracting the relevant information. Finally, differences in song duration may be linked to how 397 callers perceive the predator (visually, linked to mobbing the predator vs. acoustically, linked to 398 localising the predator). A historic observation of a real encounter with a tiger is in line with this 399 hypothesis (Uhde \& Sommer, 2002). In this instance, group A uncommonly travelled backward 400 towards the tiger's location (spotted $50 \mathrm{~m}$ away) and sang for at least one hour and a half, 401 suggesting that singing primarily serves first and foremost as a predator deterrence device and 402 second as a conspecific warning signal if the exact location of the predator is unknown and 403 groups feel reasonably safe.

404

405 Singing as territorial behaviour 
406 In related research (J Andrieu, 2012-2014, unpublished data a), we have shown that spatial 407 proximity between two neighbouring groups tends to lead to duet song overlap, due to the fact 408 that the second group refuses to delay singing until the first group has finished their duet song. 409 This behaviour is attenuated by kinship, to the effect that related individuals are more likely to 410 respect each other's duets, even if produced at close distances. In the current study, all study 411 groups started producing duet songs while the playback duet song was still being broadcast, 412 suggesting that the manipulation was perceived as a territorial threat. Unfortunately, we could 413 not statistically analyse the effect of genetic relatedness in this study because the sample size was 414 too small ( $\mathrm{N}=6$ groups).

415

416 Singing as compositional behaviour

417 Although our study has focussed on song comprehension, it has also generated a more detailed 418 picture of the structural composition of white-handed gibbon songs. Clarke et al (2006) already 419 noted that the duet songs of gibbon groups that were not well habituated to human observers 420 contained elements that were normally found in predator songs, notably 'sharp wows'. In our

421

422

423

424 425

426

427 428

\section{Conclusion}

435 Gibbons play an interesting role in questions about the biological roots of language-related 436 study, all groups were fully habituated to human presence, yet some groups still produced 'sharp wow' notes in their duet song replies to playbacks of neighbouring duet songs, but also in 4 of 5 natural duet songs (Table 3), of which 3 were involved in duet counter-signing exchanges with previous duetting direct neighbours. Another structural subtlety concerned the use of 'wa-oo' notes. This note type was near absent in predator songs but common in the early parts of the duet songs, especially the ones given in response to duet song playbacks. We attribute these findings to the fact that our experimental design consisted of playbacks of song recordings at relatively close distances (about 150m), which may have been perceived as a social threat by some groups, either territorial or risk of partner defection. Future work is required to test whether these notes are actively used to describe events in hierarchically structured ways (main: predatory threat: $\mathrm{y} / \mathrm{n}$; subsidiary: social threat $\mathrm{y} / \mathrm{n}$ ), similar to how human represent natural events as tree structures in both cognition and language (Zuberbühler, 2019b).

\footnotetext{
capacities in humans. Although part of the Hominoidae family, they maintain a relatively basal
} 
437 position in their phylogeny by diverging from the great apes some 16 million years ago (Carbone 438 et al., 2014). Nevertheless, gibbons show interesting vocal behaviour by which a small repertoire 439 of acoustically distinct notes are combined into higher-order structures, such as figures, phrases 440 and sequences, assembled into different song types (Raemaekers, Raemaekers \& Haimoff, 441 1984a; Clarke, Reichard \& Zuberbühler, 2006; J Andrieu, 2012-2014, unpublished data b).

442 These findings have some implications for the ongoing debate about syntax and phonology in 443 animal communication (Bolhuis et al., 2018; Townsend et al., 2018).

445 In a previous study (Clarke et al., 2006), structural differences between gibbon song types were 446 explained as a case of animal syntax although this was based on a very broad definition of the term. An alternative, more restricted definition of syntax invokes semantics, notably that the units subjected to syntactic operations (e.g. the notes) are meaningful, for which there is 449 currently no evidence in gibbon song.

450

Whatever definition is applied, gibbon song has several levels of complexity and future research 452 should be directed at the acoustic variation in the different note types and their combinations. For example, in the current study we found that the production of 'wa-oo' and 'sharp wow' notes might be linked with perceived social threat. So far, systematic analyses have been restricted to the early parts of the song (based on the assumption that predator information should be conveyed early on) with individual contributions not systematically studied. Traditional acoustic analysis may not suffice to make meaningful progress, suggesting that automated call extraction and categorisation techniques may offer more promise to explore the full combinatorial, hierarchical and compositional capacity of gibbon song (Kershenbaum, 2014; Kershenbaum et al., 2014, 2016; Kershenbaum \& Garland, 2015; Fedurek, Zuberbühler \& Dahl, 2016).

\section{Acknowledgements}

We are thankful to the National Research Council of Thailand (NRCT), the National Park, Wildlife and Plant Conservation Department (DNP), and the superintendent of Khao Yai National Park for giving us permission to conduct this research. We thank Melanie Jackson, 


\section{References}

471 Aguilar de Soto N, Madsen PT, Tyack P, Arranz P, Marrero J, Fais A, Revelli E, Johnson M.

472

473

474

475

476

477

478

479

480

481

482

483

484

485

486

487

488

489

490

491
2012. No shallow talk: Cryptic strategy in the vocal communication of Blainville's beaked whales. Marine Mammal Science 28:E75-E92.

Andrieu J, Neumann C, Malaivijitnond S, Reichard UH, Zuberbühler K. 2012-2014. Nepotism favours intergroup cooperation in gibbons. Unpublished data a.

Andrieu J, Penny SG, Bouchet H, Malaivijitnond S, Reichard UH, Zuberbühler K. 2012-2014. Gibbon songs refer to external events. Unpublished data b.

Arnold K, Zuberbühler K. 2006a. Language evolution: Semantic combinations in primate calls. Nature 441:303-303. DOI: 10.1038/441303a.

Arnold K, Zuberbühler K. 2006b. The alarm-calling system of adult male putty-nosed monkeys, Cercopithecus nictitans martini. Animal Behaviour 72:643-653. DOI: 10.1016/j.anbehav.2005.11.017.

Arnold K, Zuberbühler K. 2013. Female Putty-Nosed Monkeys Use Experimentally Altered Contextual Information to Disambiguate the Cause of Male Alarm Calls. PLoS ONE 8. DOI: DOI 10.1371/journal.pone.0065660.

Barelli C, Mundry R, Heistermann M, Hammerschmidt K. 2013. Cues to Androgens and Quality in Male Gibbon Songs. PLoS ONE 8:e82748. DOI: 10.1371/journal.pone.0082748.

Benjamini Y, Hochberg Y. 1995. Controlling the False Discovery Rate: A Practical and Powerful Approach to Multiple Testing. Journal of the Royal Statistical Society. Series B (Methodological) 57:289-300.

Boissy A. 1995. Fear and fearfulness in animals. The quarterly review of biology 70:165-191. 
492 Bolhuis JJ, Beckers GJ, Huybregts MA, Berwick RC, Everaert MB. 2018. Meaningful syntactic $493 \quad$ structure in songbird vocalizations? PLoS biology 16:e2005157.

494 Carbone L, Alan Harris R, Gnerre S, Veeramah KR, Lorente-Galdos B, Huddleston J, Meyer TJ, 495 Herrero J, Roos C, Aken B, Anaclerio F, Archidiacono N, Baker C, Barrell D, Batzer

496

497

498

499

500

501

502

503

504

505

506

507

508

509

510

511

512 MA, Beal K, Blancher A, Bohrson CL, Brameier M, Campbell MS, Capozzi O, Casola C, Chiatante G, Cree A, Damert A, de Jong PJ, Dumas L, Fernandez-Callejo M, Flicek P, Fuchs NV, Gut I, Gut M, Hahn MW, Hernandez-Rodriguez J, Hillier LW, Hubley R, Ianc B, Izsvák Z, Jablonski NG, Johnstone LM, Karimpour-Fard A, Konkel MK, Kostka D, Lazar NH, Lee SL, Lewis LR, Liu Y, Locke DP, Mallick S, Mendez FL, Muffato M, Nazareth LV, Nevonen KA, O’Bleness M, Ochis C, Odom DT, Pollard KS, Quilez J, Reich D, Rocchi M, Schumann GG, Searle S, Sikela JM, Skollar G, Smit A, Sonmez K, Hallers B ten, Terhune E, Thomas GWC, Ullmer B, Ventura M, Walker JA, Wall JD, Walter L, Ward MC, Wheelan SJ, Whelan CW, White S, Wilhelm LJ, Woerner AE, Yandell M, Zhu B, Hammer MF, Marques-Bonet T, Eichler EE, Fulton L, Fronick C, Muzny DM, Warren WC, Worley KC, Rogers J, Wilson RK, Gibbs RA. 2014. Gibbon genome and the fast karyotype evolution of small apes. Nature 513:195-201. DOI: 10.1038 /nature13679.

Carnap R. 1988. Meaning and necessity: a study in semantics and modal logic. University of Chicago Press.

Clarke E, Reichard UH, Zuberbühler K. 2006. The Syntax and Meaning of Wild Gibbon Songs. PLoS ONE 1:e73. DOI: 10.1371/journal.pone.0000073. 
513 Clarke E, Reichard UH, Zuberbühler K. 2012. The anti-predator behaviour of wild white-handed 514 gibbons (Hylobates lar). Behavioral Ecology and Sociobiology 66:85-96. DOI:

$515 \quad 10.1007 / \mathrm{s} 00265-011-1256-5$.

516 Clarke E, Reichard UH, Zuberbühler K. 2015. Context-specific close-range "hoo" calls in wild 517 518 gibbons (Hylobates lar). BMC Evolutionary Biology 15:56. DOI: 10.1186/s12862-0150332-2.

519

520

521

Clink DJ, Bernard H, Crofoot MC, Marshall AJ. 2017. Investigating individual vocal signatures and small-scale patterns of geographic variation in female Bornean gibbon (Hylobates muelleri) great calls. International Journal of Primatology 38:656-671.

522 Dunn OJ. 1964. Multiple comparisons using rank sums. Technometrics 6:241-252.

523 Ellefson JO. 1968. Territorial behavior in the common white-handed gibbon, Hylobates lar. In: 524 Linn. Primates: Studies in adaptation and variability. 180-199.

525 Fedurek P, Zuberbühler K, Dahl CD. 2016. Sequential information in a great ape utterance. 526 Scientific reports 6:38226.

527 Fischer J, Hammerschmidt K. 2006. Vocal communication in Barbary macaques: a comparative 528 perspective. The Barbary Macaque: Biology, Management and Conservation:63.

529 Fischer J, Hammerschmidt K, Todt D. 1995. Factors affecting acoustic variation in 530 Barbary-macaque (Macaca sylvanus) disturbance calls. Ethology 101:51-66.

531 Fischer J, Hammerschmidt K, Todt D. 1998. Local variation in Barbary macaque shrill barks. Animal Behaviour 56:623-629.

533 Geissmann T. 1999. Duet songs of the siamang, Hylobates syndactylus: II. Testing the pairbonding hypothesis during a partner exchange. Behaviour 136:1005-1039. 
535 Geissmann T. 2002. Duet-splitting and the evolution of gibbon songs. Biol. Rev. 77:57-76. DOI:

$536 \quad 10.1017\}$ S1464793101005826.

537 Geissmann T, Orgeldinger M. 2000. The relationship between duet songs and pair bonds in 538 siamangs, Hylobates syndactylus. Animal Behaviour 60:805-809. DOI:

539 10.1006/anbe.2000.1540.

540 Grassman LI. 2001. Spatial ecology and conservation of the felid community in Phu Khieo 541 Wildlife Sanctuary, Thailand. Report to Cat Action Treasury.

542 Grice HP. 1969. Utterer's meaning and intentions. The philosophical review 78:147-177.

543 Grow NB. 2019. Cryptic Communication in a Montane Nocturnal Haplorhine, Tarsius pumilus. $544 \quad$ Folia Primatologica 90:404-421.

545 Haimoff EH. 1981. Video Analysis of Siamang (Hylobates Syndactylus) Songs. Behaviour 546 76:128-151. DOI: 10.1163/156853981X00040.

547 Haimoff EH. 1984. Acoustic and organizational features of gibbon songs. In: The lesser apes: 548 Evolutionary and Behavioural Biology. Edinburgh: H. Preuschoft, D. J. Chivers, W. Y. Brockelman and N. Creel, 333-353.

550 Keenan S, Lemasson A, Zuberbühler K. 2013. Graded or discrete? A quantitative analysis of 551 Campbell's monkey alarm calls. Animal Behaviour 85:109-118. DOI:

552 10.1016/j.anbehav.2012.10.014.

553

Kershenbaum A. 2014. Entropy rate as a measure of animal vocal complexity. Bioacoustics 23:195-208.

555

Kershenbaum A, Blumstein DT, Roch MA, Akçay Ç, Backus G, Bee MA, Bohn K, Cao Y, 556 Carter G, Cäsar C. 2016. Acoustic sequences in non-human animals: a tutorial review and prospectus. Biological Reviews 91:13-52. 
558 Kershenbaum A, Bowles AE, Freeberg TM, Jin DZ, Lameira AR, Bohn K. 2014. Animal vocal 559 sequences: not the Markov chains we thought they were. Proceedings of the Royal $560 \quad$ Society B: Biological Sciences 281:20141370.

561 Kershenbaum A, Garland EC. 2015. Quantifying similarity in animal vocal sequences: Which 562 metric performs best? Methods in Ecology and Evolution 6:1452-1461.

563 Koda H, Lemasson A, Oyakawa C, Pamungkas J, Masataka N. 2013. Possible role of mother564 daughter vocal interactions on the development of species-specific song in gibbons. PloS $565 \quad$ one $8: \mathrm{e} 71432$.

566 Lemasson A, Ouattara K, Bouchet H, Zuberbühler K. 2010. Speed of call delivery is related to 567 context and caller identity in Campbell's monkey males. Naturwissenschaften 97:1023568 1027. DOI: $10.1007 / \mathrm{s} 00114-010-0715-6$.

Marshall JT, Marshall ER. 1976. Gibbons and Their Territorial Songs. Science 193:235-237.

570 DOI: $10.1126 /$ science.193.4249.235.

571

572

573

574 575 576

577

578

579

Matsudaira K, Ishida T, Malaivijitnond S, Reichard UH. 2018. Short dispersal distance of males in a wild white-handed gibbon (Hylobates lar) population. American Journal of Physical Anthropology 1. DOI: 10.1002/ajpa.23603.

Mitani JC. 1985. Gibbon song duets and intergroup spacing. Behaviour:59-96.

Mundry R, Fischer J. 1998. Use of statistical programs for nonparametric tests of small samples often leads to incorrect Pvalues: examples from Animal Behaviour. Animal Behaviour 56:256-259. DOI: 10.1006/anbe.1998.0756.

Ouattara K, Lemasson A, Zuberbühler K. 2009a. Campbell's Monkeys Use Affixation to Alter Call Meaning. PLoS ONE 4:e7808. 
580 Ouattara K, Lemasson A, Zuberbühler K. 2009b. Campbell's monkeys concatenate vocalizations

581

582

583

584

585

586

587

588

589

590

591

592

593

594

595

596

597

598

599

600

601 into context-specific call sequences. Proceedings of the National Academy of Sciences 106:22026-22031.

Ouattara K, Zuberbühler K, N'goran EK, Gombert J-E, Lemasson A. 2009. The alarm call system of female Campbell's monkeys. Animal Behaviour 78:35-44. DOI: 10.1016/j.anbehav.2009.03.014.

Oyakawa C, Koda H, Sugiura H. 2007. Acoustic features contributing to the individuality of wild agile gibbon (Hylobates agilis agilis) songs. American Journal of Primatology 69:777790. DOI: 10.1002/ajp.20390.

R core Team. 2018. R: A language and environment for statistical computing. Vienna, Austria: R Foundation for Statistical Computing.

Rabinowitz A, Andau P, Chai PPK. 1987. The clouded leopard in Malaysian Borneo. Oryx 21:107-111.

Raemaekers JJ, Raemaekers PM. 1985a. Field playback of loud calls to gibbons (Hylobates lar): territorial, sex-specific and species-specific responses. Animal Behaviour 33:481-493.

Raemaekers PM, Raemaekers JJ. 1985b. Long-range vocal interactions between groups of gibbons (Hylobates lar). Behaviour 95:26-44.

Raemaekers JJ, Raemaekers PM, Haimoff EH. 1984a. Loud calls of the gibbon (Hylobates lar): repertoire, organisation and context. Behaviour 91:146-189.

Schel AM, Tranquilli S, Zuberbühler K. 2009. The alarm call system of two species of blackand-white colobus monkeys (Colobus polykomos and Colobus guereza). Journal of Comparative Psychology 123:136-150. DOI: 10.1037/a0014280. 
602 Scott-Phillips TC. 2010. Animal communication: insights from linguistic pragmatics. Animal 603 Behaviour 79:e1-e4.

604 Seyfarth R, Cheney D. 2018. Pragmatic flexibility in primate vocal production. Current Opinion 605 in Behavioral Sciences 21:56-61. DOI: 10.1016/j.cobeha.2018.02.005.

606 Seyfarth RM, Cheney DL, Marler P. 1980a. Monkey responses to three different alarm calls: 607 evidence of predator classification and semantic communication. Science 210:801-803.

608 Seyfarth RM, Cheney DL, Marler P. 1980b. Vervet Monkey Alarm Calls: Semantic 609 Communication in a Free-Ranging Primate. Animal Behaviour 28:1070-1094.

610 Siegel S, Castellan NJ. 1988. The Friedman two-way analysis of variance by ranks.

$611 \quad$ Nonparametric statistics for the behavioral sciences:174-184.

612 Slocombe KE, Zuberbühler K. 2005. Functionally Referential Communication in a Chimpanzee. 613 Current Biology 15:1779-1784. DOI: 10.1016/j.cub.2005.08.068.

614 Smith WJ. 1977. The behavior of communicating: an ethological approach Harvard University 615 Press. Cambridge, $M A$.

616 Terleph TA, Malaivijitnond S, Reichard UH. 2015. Lar gibbon (Hylobates lar) great call reveals 617 individual caller identity: Lar Gibbon Great Calls. American Journal of Primatology 618 77:811-821. DOI: 10.1002/ajp.22406.

619 Terleph TA, Malaivijitnond S, Reichard UH. 2016. Age related decline in female lar gibbon 620 great call performance suggests that call features correlate with physical condition. $B M C$ Evolutionary Biology 16:4. DOI: 10.1186/s12862-015-0578-8.

622 Terleph TA, Malaivijitnond S, Reichard UH. 2017. Male white-handed gibbons flexibly time 623 duet contributions. Behavioral Ecology and Sociobiology 72. 
624 Townsend SW, Engesser S, Stoll S, Zuberbühler K, Bickel B. 2018. Compositionality in animals 625 and humans. PLoS biology 16:e2006425.

626 Uhde NL, Sommer V. 2002. Antipredatory behavior in gibbons (Hylobates lar, Khao Yai, 627 Thailand). In: Khao Yai. 168-291.

628 Zuberbühler K. 2000a. Referential labelling in Diana monkeys. Animal Behaviour 59:917-927. 629 DOI: 10.1006/anbe.1999.1317.

630 Zuberbühler K. 2000b. Causal cognition in a non-human primate: field playback experiments 631 with Diana monkeys. Cognition 76:195-207.

632 Zuberbühler K. 2019a. Evolutionary roads to syntax. Animal Behaviour 151:259-265. DOI: $633 \quad$ 10.1016/j.anbehav.2019.03.006.

634 Zuberbühler K. 2019b. Syntax and compositionality in animal communication. Phil. Trans. R. 635 Roc. Lond. B. DOI: https://royalsocietypublishing.org/doi/pdf/10.1098/rstb.2019.0062.

636 Zuberbühler K, Jenny D, Bshary R. 1999. The predator deterrence function of primate alarm 637 calls. Ethology 105:477-490.

638 
Figure 1

Song note repertoire of white-handed gibbons (Raemaekers, Raemaekers \& Haimoff, 1984a; Clarke, Reichard \& Zuberbühler, 2006).

Note types a) 'hoo'; b) 'oo'; c) 'wa'; d) 'leaning wa'; e) 'wa-oo'; f) 'sharp wow'; g) 'other'; h) 'other'. Songs were digitized using Cool Edit Pro 2.1.; spectrograms were drawn using 21.6 $\mathrm{Hz}$ filter bandwidth, $2.69 \mathrm{~Hz}$ frequency resolution, $33.3 \mathrm{~ms}$ time grid resolution and a Hanning window function. 

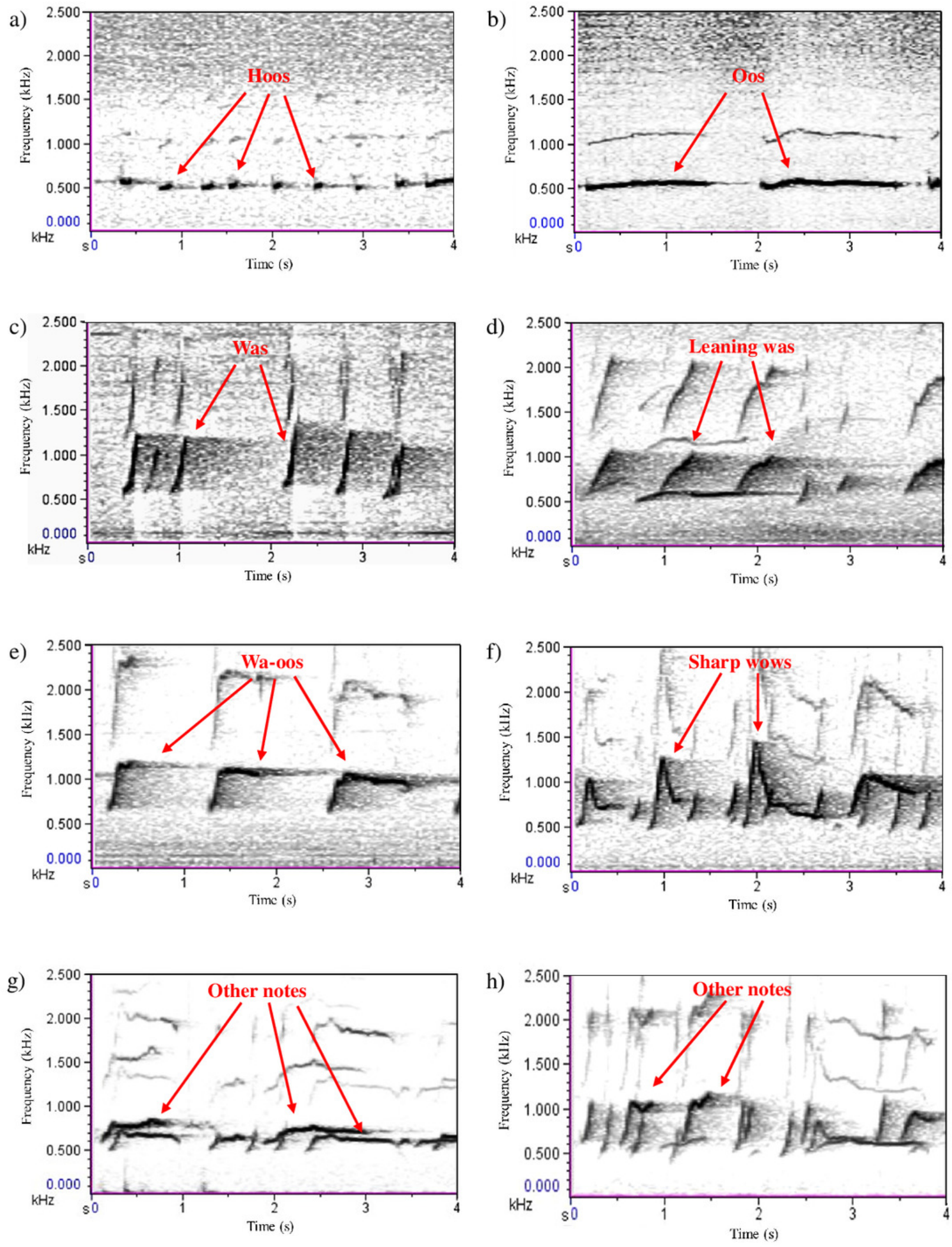
Figure 2

Schematic representation of the structural differences between a) duet and b) predator songs (Clarke, Reichard \& Zuberbühler, 2006) .

a)

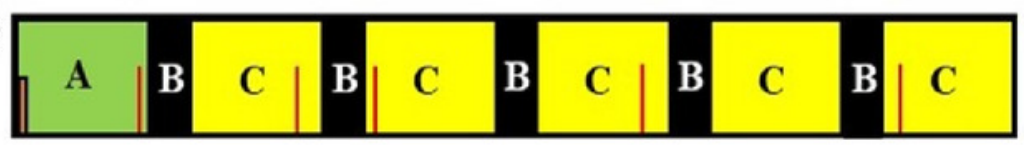

A Introductory sequence

B Great call sequence

C Interlude sequence

$\square$ Introductory 'Hoo' note series

| 'Sharp wow' note

b)

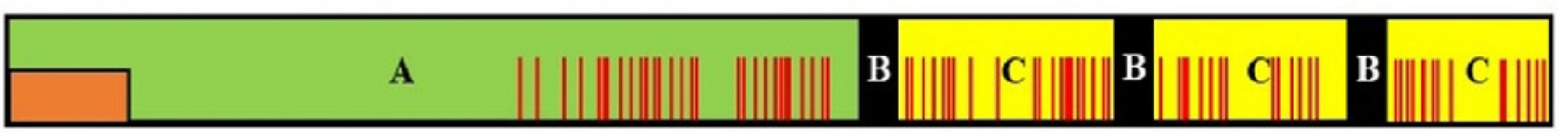

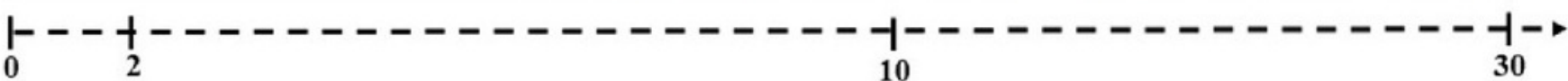

Time (min) 


\section{Figure 3}

a) Clouded leopard model used to elicit predator songs (Photo credit: Julie Andrieu); b) real clouded leopard, Neofelis nebulosa (Image credit: goodfreephotos.com at https://www.goodfreephotos.com/animals/mammals/clouded-leopard.jpg.php)
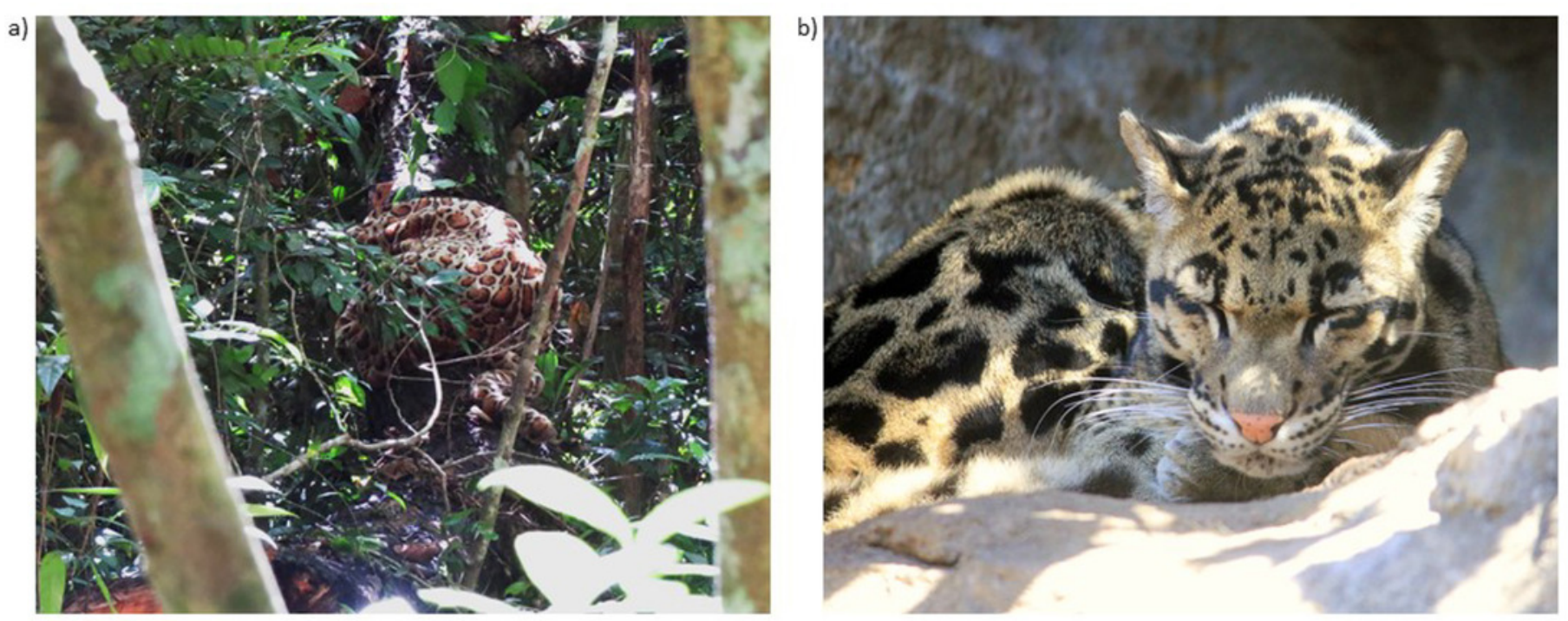
Figure 4

a) Latency and b) duration of the male gibbons' first gaze towards the speaker broadcasting a simulated neighbouring male's song (duet vs. predator song condition). 

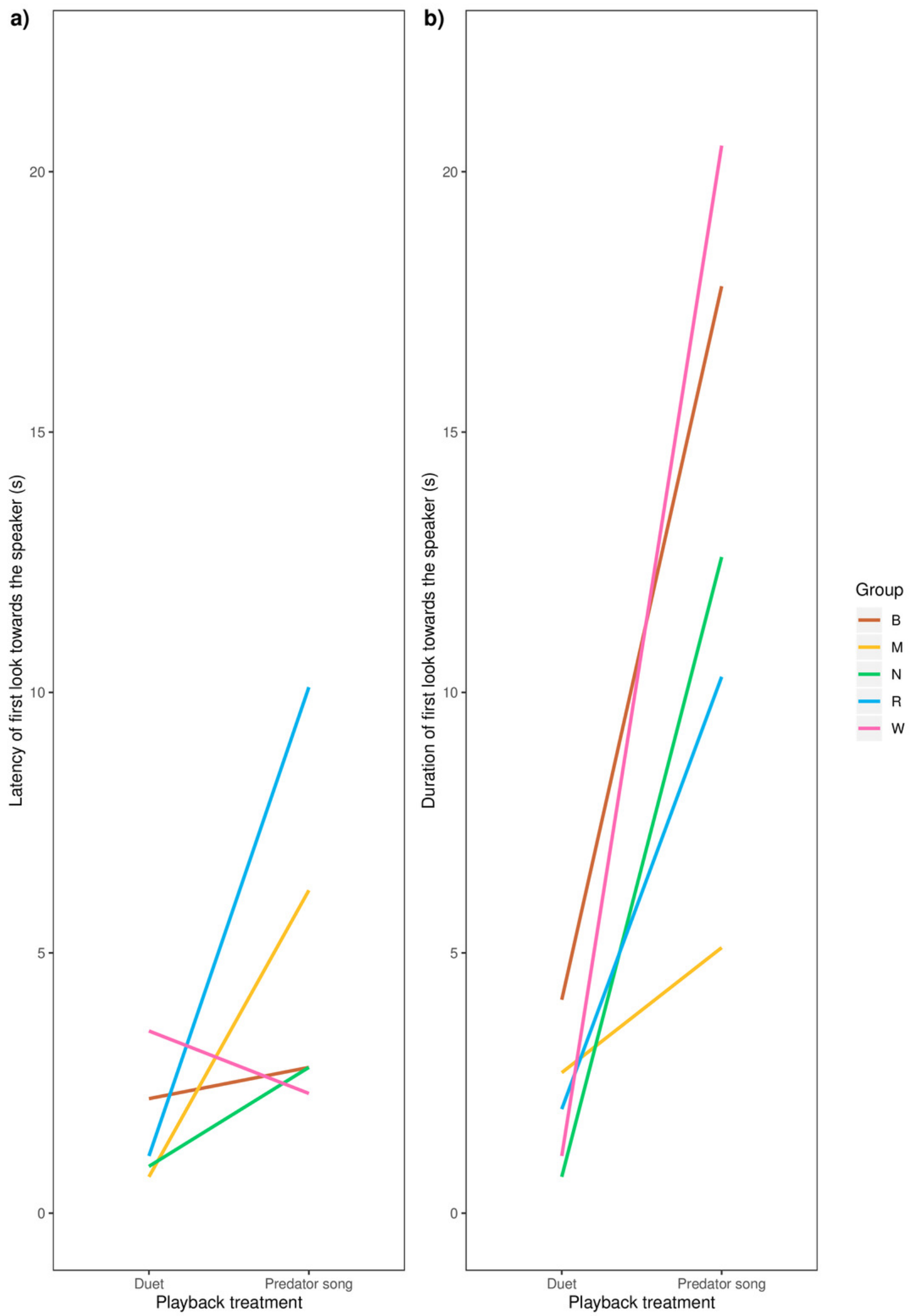

Peer) reviewing PDF | (2019:12:43728:2:1:NEW 9 Jun 2020) 
Figure 5

Proportion of vigilance behaviours displayed by males in each playback condition $(\mathrm{N}=6$ males). 


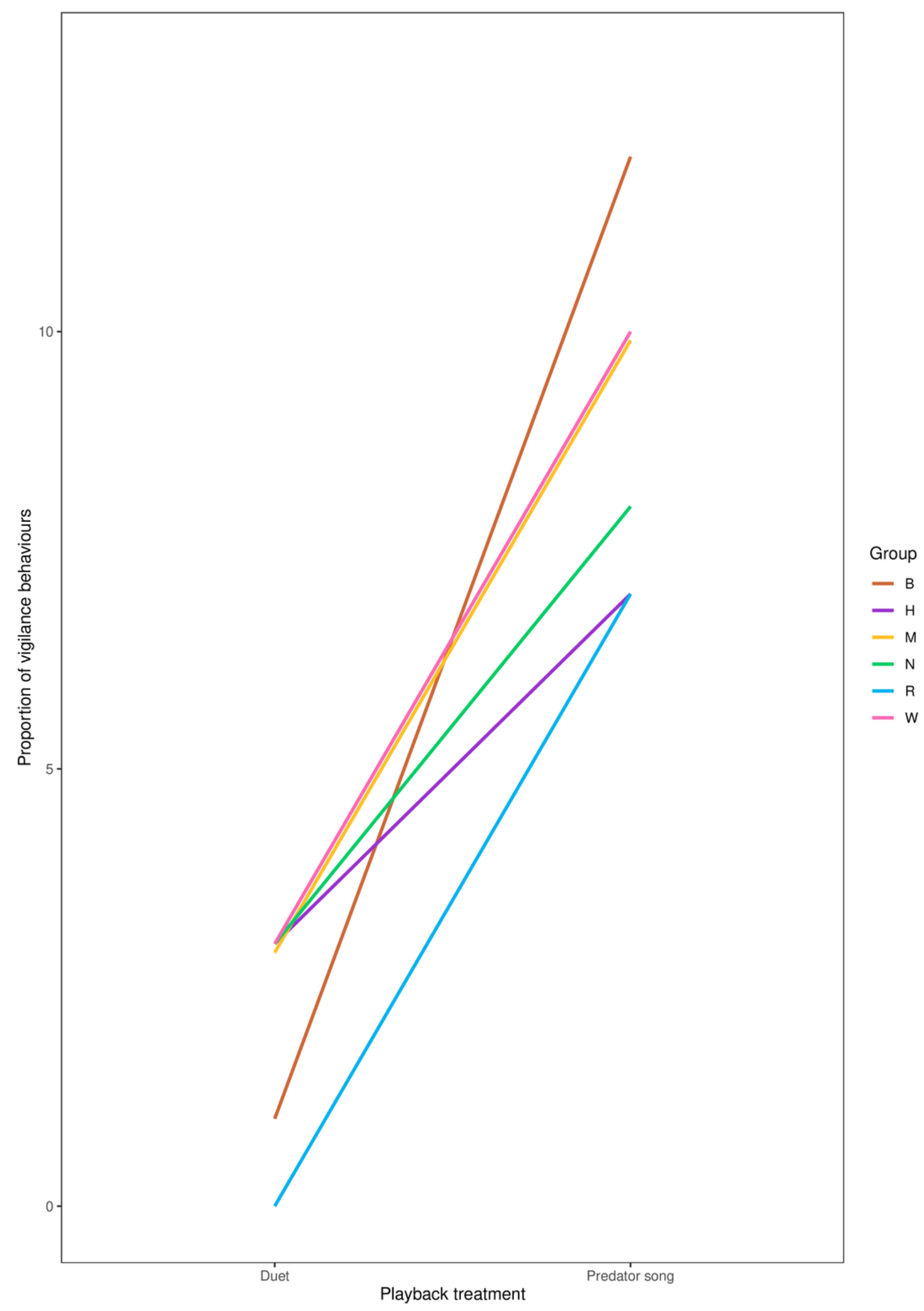

Peer] reviewing PDF | (2019:12:43728:2:1:NEW 9 Jun 2020) 
Figure 6

Variation of a) ground, b) canopy, c) speaker and d) group member gazes between playback treatment ( $\mathrm{N}=6$ males). 

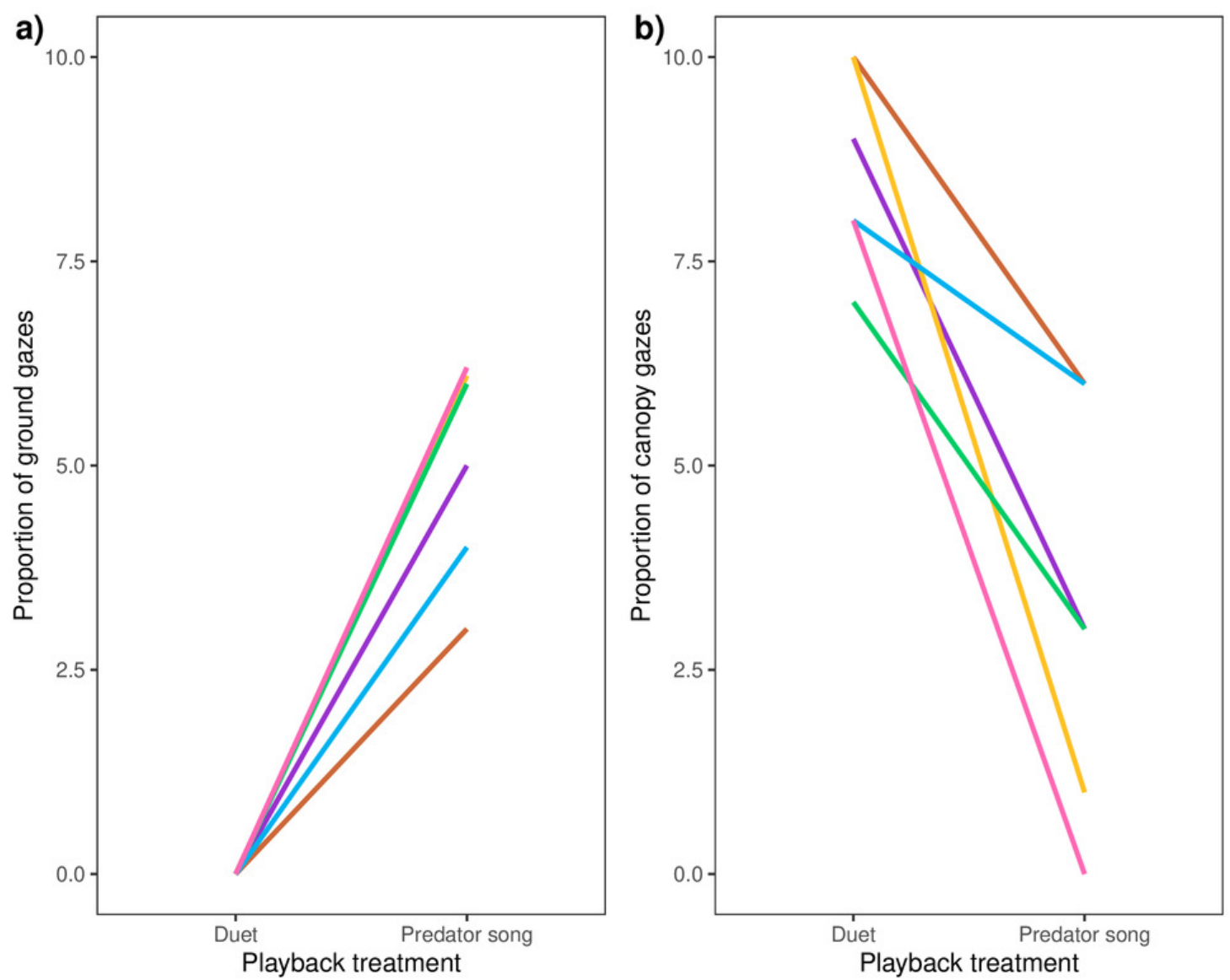

Group
$-\mathrm{B}$
$-\mathrm{H}$
$-\mathrm{M}$
$-\mathrm{N}$
$-\mathrm{R}$
$-\mathrm{W}$
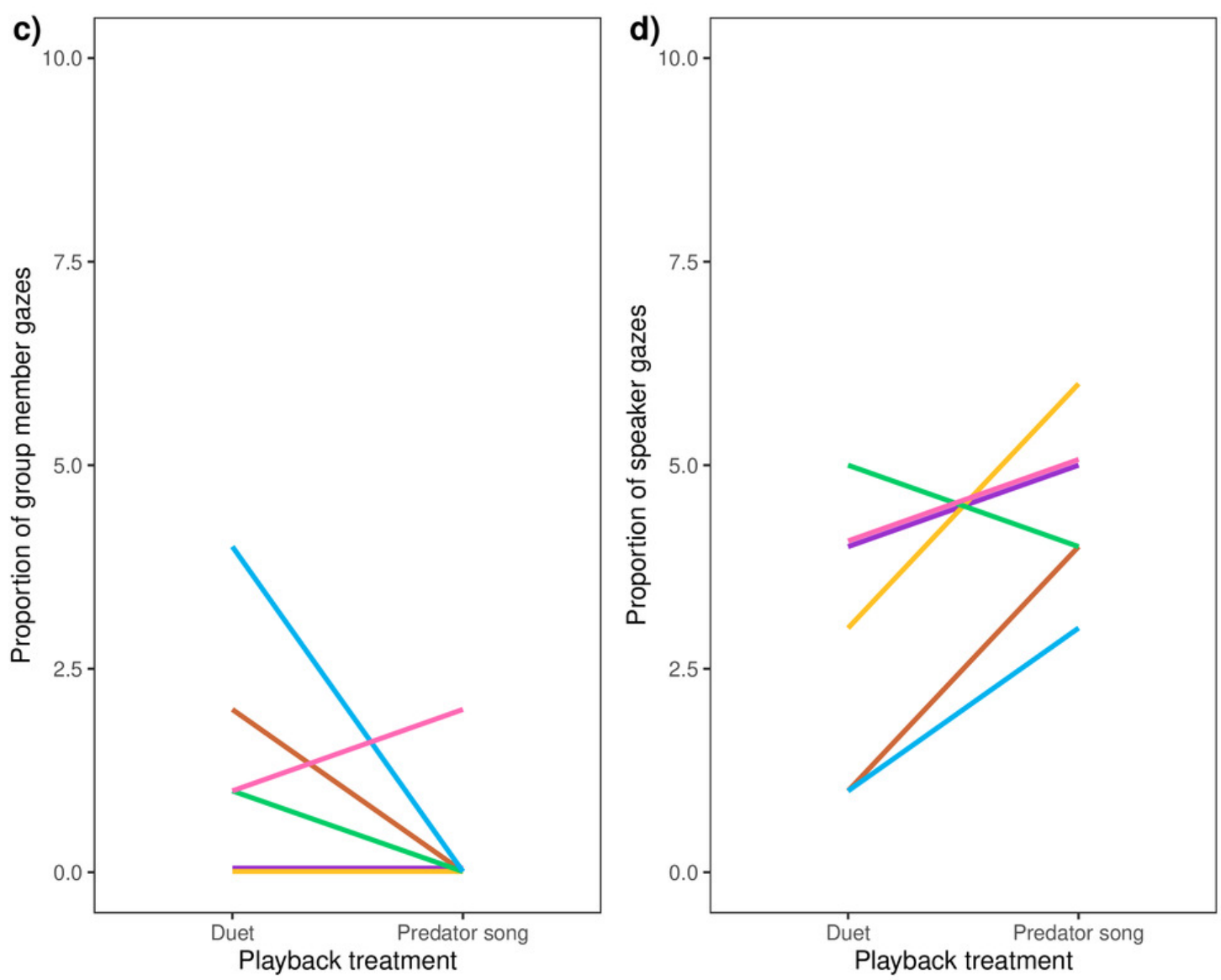

Peer] reviewing PDF | (2019:12:43728:2:1:NEW 9 Jun 2020) 


\section{Table $\mathbf{1}$ (on next page)}

Composition of study groups at the Mo Singto-Klong E-Tau research area (August 2014)

*Multi-male group; $M=$ male, $\mathrm{F}=$ female, ?=sex unknown, $\mathrm{A}=$ Adult (age $>8 y e a r s), S A=$ Subadult (5-8 years), J=juvenile ( $2-5$ years), I=infant (<2years). $X=$ tested group, $-=$ group not tested. 'no data on latency and duration of first look to speaker due to technical problems (duet playback: female filmed erroneously; predator playback: male moved out of sight). 


\begin{tabular}{|c|c|c|c|c|}
\hline Group & $\mathrm{N}$ individuals & Group composition & Tested & Song provider for \\
\hline$A^{*}$ & 3 & $2 \mathrm{AM}, 1 \mathrm{AF}$ & -- & group $\mathrm{H}$ \\
\hline B* & 5 & 2AM, 1AF, 1JF, 1I? & yes & -- \\
\hline BD & 3 & 1AM, 1AF, 1I? & -- & -- \\
\hline $\mathbf{C}$ & 3 & 1AM, 1AF, 1I? & -- & -- \\
\hline $\mathbf{E}$ & 3 & $1 \mathrm{AM}, 1 \mathrm{AF}, 1 \mathrm{JM}$ & -- & -- \\
\hline $\mathbf{H}^{\dagger}$ & 4 & $1 \mathrm{AM}, 1 \mathrm{AF}, 1 \mathrm{JF}, 1 \mathrm{I} ?$ & yes & -- \\
\hline $\mathbf{M}$ & 5 & 1AM, 1AF, 1SAF, 1JM, 1I? & yes & group $\mathrm{R}$ \\
\hline $\mathbf{N *}$ & 6 & 2AM, 1AF, 1SAM, 1JF, 1I? & yes & group $\mathrm{M}$ \\
\hline NOS* & 5 & 2AM, 1AF, 1J?, 1I? & -- & -- \\
\hline $\mathbf{R}$ & 4 & $1 \mathrm{AM}, 1 \mathrm{AF}, 1 \mathrm{AF}, 1 \mathrm{I} ?$ & yes & -- \\
\hline $\mathbf{S}$ & 3 & $1 \mathrm{AM}, 1 \mathrm{AF}, 1 \mathrm{JM}$ & -- & group W \\
\hline $\mathbf{T}$ & 5 & 1AM, 1AF, 1SAM, 1JM, 1I? & -- & group B \\
\hline $\mathbf{W}^{*}$ & 4 & 2AM, 1AF, 1I? & yes & group $\mathrm{N}$ \\
\hline
\end{tabular}

1 *Multi-male group; $\mathrm{M}=$ male, $\mathrm{F}=$ female, ?=sex unknown, $\mathrm{A}=$ Adult (age $>$ 8years), $\mathrm{SA}=\mathrm{Sub}$-adult

2 (5-8 years), $\mathrm{J}=$ juvenile (2-5 years), $\mathrm{I}=$ infant ( $<2$ years). $\mathrm{X}=$ tested group, $-=$ group not tested. ${ }^{\dagger}$ no

3 data on latency and duration of first look to speaker due to technical problems (duet playback:

4 female filmed erroneously; predator playback: male moved out of sight). 


\section{Table 2 (on next page)}

Behavioural response variables extracted for the primary males in both playback conditions 


\begin{tabular}{|c|c|c|}
\hline Behaviour & \multicolumn{2}{|c|}{ Definition } \\
\hline Feeding & \multicolumn{2}{|c|}{ Handling or consuming food items } \\
\hline Resting & \multicolumn{2}{|r|}{ Prolonged stationary position, with or without eyes closed } \\
\hline Grooming & \multicolumn{2}{|r|}{ Auto- or allo-grooming (giver and receiver identity were collected) } \\
\hline Social & \multicolumn{2}{|c|}{ Mating, play, aggressive, or parental behaviour } \\
\hline Moving & \multicolumn{2}{|r|}{ Travel within or between trees (at least 2 metres) } \\
\hline Vigilance & \multicolumn{2}{|r|}{ Scanning the environment, head rotating by at least $45^{\circ}$ (Koenig 1998) } \\
\hline Other & \multicolumn{2}{|r|}{ Behaviour not classified into any of the above categories } \\
\hline Body Position & \multicolumn{2}{|c|}{ Definition } \\
\hline Hanging & \multicolumn{2}{|r|}{ Suspended in the air, grabbing a branch or a tree part with at least one arm } \\
\hline Sitting/Lying & \multicolumn{2}{|r|}{ Sitting on a branch or on the ground / Resting in horizontal position } \\
\hline \multicolumn{3}{|c|}{ Gaze direction (staring at a specific location/direction/animal/person for $\geq 3 \mathrm{~s}$ ) } \\
\hline Speaker & \multicolumn{2}{|c|}{ Staring in the direction of the speaker } \\
\hline Ground & \multicolumn{2}{|c|}{ Looking towards or actively scanning the ground } \\
\hline Canopy & \multicolumn{2}{|r|}{$\begin{array}{l}\text { Looking around, or towards a specific location in the trees at the same elevation } \\
\text { as the animal location }\end{array}$} \\
\hline Sky & \multicolumn{2}{|c|}{ Looking up at the sky } \\
\hline Group member & \multicolumn{2}{|r|}{ Looking at a group member (the identity of the receiver was collected) } \\
\hline Observer & \multicolumn{2}{|c|}{ Looking at the observer } \\
\hline Elsewhere & \multicolumn{2}{|r|}{ Looking in a direction that cannot be classified into any of the above categories } \\
\hline Nowhere & \multicolumn{2}{|c|}{ Resting with eyes closed } \\
\hline \multicolumn{3}{|c|}{ Other measurements $\quad$ Definition } \\
\hline \multicolumn{2}{|l|}{ Elevation (m) } & Height of the animal in relation to the ground \\
\hline \multicolumn{2}{|l|}{ Proximity (m) } & Distance between the two focal individuals (paired male and female) \\
\hline \multicolumn{2}{|c|}{ Defecation/Urination } & Exuding faeces and/or urine \\
\hline \multicolumn{2}{|l|}{ Dropping branch } & Individuals shaking branch(es) so as it ended up falling on the ground \\
\hline \multicolumn{2}{|c|}{$\begin{array}{l}\text { Latency of first look } \\
\text { towards the speaker (s) }\end{array}$} & Time elapsed between stimulus onset and first look towards the speaker \\
\hline
\end{tabular}




\begin{tabular}{|l|l|}
\hline $\begin{array}{l}\text { Duration of first look } \\
\text { towards the speaker }(\mathrm{s})\end{array}$ & Duration of first gaze directed towards the speaker location \\
\hline
\end{tabular}

1 


\section{Table 3 (on next page)}

Comparison of songs given in response to playbacks of duet songs $(\mathrm{N}=5)$, spontaneous duet songs $(\mathrm{N}=5)$ and predator songs $(\mathrm{N}=5)$ by the same five groups (Kruskal-Wallis rank sum test).

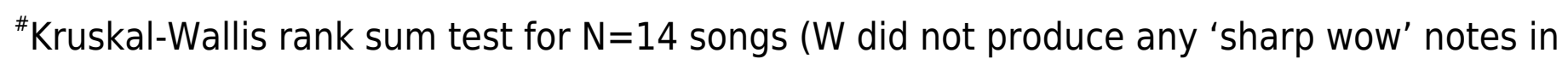
spontaneous duet; $\mathrm{N}_{\text {duet }}=4, \mathrm{~N}_{\text {predator }}=5, \mathrm{~N}_{\text {response }}=5$ ); $* P<0.05$ corrected; $* *$ means $\pm \mathrm{SD}$. 


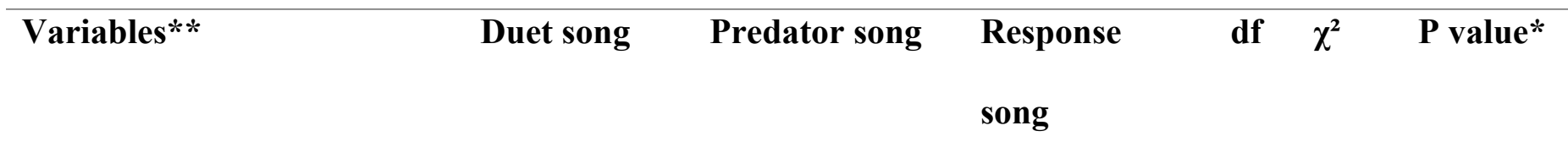
Duration introductory 'hoo' $8.0 \pm 3.1$
$23.4 \pm 6.7$
$4.7 \pm 2.7$
$2 \quad 10.5<0.05$

series (s)

\begin{tabular}{lllllll}
\hline N introductory & $11.0 \pm 4.5$ & $48.8 \pm 14.4$ & $7.4 \pm 2.7$ & 2 & 10.2 & $<0.05$ \\
'hoo' notes & & & & & \\
& & & & & \\
\hline Song duration (s) & $789.4 \pm 294.8$ & $2396.4 \pm 775.8$ & $1006.8 \pm 122.3$ & 2 & 10.2 & $<0.05$
\end{tabular}

\begin{tabular}{lllllll}
\hline Latency to $1^{\text {st }}$ great call (s) & $101.3 \pm 33.5$ & $816.4 \pm 368.0$ & $99.0 \pm 41.1$ & 2 & 9.5 & $<0.05$
\end{tabular}

\begin{tabular}{lllllll}
\hline Latency to $1^{\text {st }}$ 'sharp wow' & $78.1 \pm 31.1$ & $370.5 \pm 183.2$ & $90.8 \pm 35.9$ & 2 & 9.0 & $<0.05$
\end{tabular}

(s) \#

\begin{tabular}{lllllll}
\hline N 'sharp wows' & $9.2 \pm 8.0$ & $362.2 \pm 233.9$ & $5.6 \pm 6.0$ & 2 & 9.8 & $<0.05$
\end{tabular}

1 \#Kruskal-Wallis rank sum test for $\mathrm{N}=14$ songs (W did not produce any 'sharp wow' notes in spontaneous

2 duet; $\mathrm{N}_{\text {duet }}=4, \mathrm{~N}_{\text {predator }}=5, \mathrm{~N}_{\text {response }}=5$ ); * $\mathrm{P}<0.05$ corrected; ** means $\pm \mathrm{SD}$. 


\section{Table 4 (on next page)}

Comparison of male long-term behavioural responses between playback treatments (Wilcoxon matched-pair signed rank tests, $N=12$ playback trials, with a total of $n=156$ scan sampling observations, i.e. 13 scans per individual for 1 hour).

†All occurrence behaviours recorded over 2 hours post trial; * $P<0.05$; ** means \pm SD. 


\begin{tabular}{|c|c|c|c|c|c|}
\hline \multicolumn{2}{|l|}{ Variables $* *$} & \multirow{2}{*}{$\begin{array}{l}\text { Duet song playback } \\
1.0 \pm 1.6\end{array}$} & \multirow{2}{*}{$\begin{array}{l}\text { Predator song playback } \\
1.7 \pm 2.0\end{array}$} & \multirow{2}{*}{$\begin{array}{l}\mathbf{V} \\
5.5\end{array}$} & \multirow{2}{*}{$\begin{array}{l}\text { P value } \\
0.688\end{array}$} \\
\hline Behavioura & Grooming & & & & \\
\hline \multirow[t]{4}{*}{ I activity } & Moving & $2.0 \pm 1.3$ & $1.7 \pm 1.5$ & 13.5 & 0.594 \\
\hline & Resting & $0.8 \pm 0.8$ & $0 \pm 0$ & 10 & 0.125 \\
\hline & Feeding & $4.0 \pm 1.4$ & $0.3 \pm 0.8$ & 21 & $<0.05 *$ \\
\hline & Vigilance & $2.2 \pm 1.3$ & $9.0 \pm 2.0$ & 0 & $<0.05 *$ \\
\hline Body & Hanging & $7.2 \pm 2.5$ & $5.0 \pm 1.7$ & 3.5 & 0.188 \\
\hline position & Sitting/lying & $5.8 \pm 2.5$ & $8.0 \pm 1.7$ & 17.5 & 0.188 \\
\hline Gaze & Speaker & $3.0 \pm 1.7$ & $4.5 \pm 1.1$ & 2 & 0.125 \\
\hline \multirow[t]{3}{*}{ direction } & Canopy & $8.7 \pm 1.2$ & $3.2 \pm 2.5$ & 21 & $<0.05 *$ \\
\hline & Ground & $0 \pm 0$ & $5.0 \pm 1.3$ & 0 & $<0.05 *$ \\
\hline & Group member & $1.3 \pm 1.5$ & $0.3 \pm 0.8$ & 8.5 & 0.375 \\
\hline \multicolumn{2}{|c|}{ Elevation (m) } & $17.6 \pm 6.2$ & $25.1 \pm 7.1$ & 3 & 0.156 \\
\hline \multicolumn{2}{|c|}{ Proximity to mate (m) } & $8.9 \pm 7.3$ & $10.3 \pm 7.7$ & 7 & 0.563 \\
\hline \multicolumn{2}{|c|}{ Dropping branch $\dagger$} & $0 \pm 0$ & $0.5 \pm 0.8$ & 0 & 0.5 \\
\hline \multicolumn{2}{|c|}{ Defecation/Urination $\dagger$} & $0.3 \pm 0.5$ & $3.2 \pm 1.2$ & 0 & $<0.05 *$ \\
\hline
\end{tabular}

$1 \uparrow$ All occurrence behaviours recorded over 2 hours post trial; $* \mathrm{P}<0.05 ; * *$ means $\pm \mathrm{SD}$. 